\title{
Process signatures in regional patterns of shoreline change on annual to decadal time scales
}

\author{
Eli D. Lazarus ${ }^{1}$ and A. Brad Murray ${ }^{1}$ \\ Received 27 June 2007; revised 24 August 2007; accepted 29 August 2007; published 3 October 2007.
}

[1] Gradients in wave-driven alongshore sediment transport influence the morphologies of sediment-covered coastlines on a range of spatial and temporal scales, affecting accretion and erosion patterns relevant to human development. Recent theoretical findings predict that a correlation between shoreline change and shoreline curvature results from patterns of alongshore sediment flux; the sign (positive or negative) of that correlation depends on whether high- or low-angle waves dominated the wave climate. Using lidar surveys of the northern North Carolina coast from 1996-2005 to document shoreline change and quantify alongshore patterns of erosion and deposition, we isolate these signals diagnostic of alongshore-transport processes. Our analyses show a persistent, significant negative correlation between shoreline-position change and shoreline curvature consistent with a low-angle-dominated incident wave climate over the last decade. At large spatial scales, convex-seaward promontories have eroded landward, while concave-seaward bays have aggraded seaward, resulting in an apparent diffusion of alongshore morphological features. Citation: Lazarus, E. D., and A. B. Murray (2007), Process signatures in regional patterns of shoreline change on annual to decadal time scales, Geophys. Res. Lett., 34, L19402, doi:10.1029/ 2007 GL031047.

\section{Introduction}

[2] The relative strengths of the morphological processes that shape seaboard shorelines are typically difficult to quantify. In the last decade, the advance of remote-sensing technologies such as lidar (Light Detection and Ranging) has enabled large-scale, high-resolution, three-dimensional views of the littoral zone that offer a consistent means by which to analyze changes in shoreline morphology [Irish and White, 1998; Irish and Lillycrop, 1999; List and Farris, 1999; Brock et al., 2002; Stockdon et al., 2002; Tebbens et al., 2002; Woolard and Colby, 2002; White and Wang, 2003; Mitasova et al., 2005].

[3] Changes in shoreline shape provide clues about the forces that cause them. Recent theoretical, modeling, and data-analysis work indicates that on sediment-covered coastlines, gradients in wave-driven alongshore sediment flux affect shoreline accretion and erosion patterns on a range of spatial $\left(10^{0}-10^{3} \mathrm{~km}\right.$ ) and temporal (month to $10^{3} \mathrm{yr}$ ) scales, even on reasonably straight shorelines with

\footnotetext{
${ }^{1}$ Division of Earth and Ocean Sciences, Nicholas School of the Environment and Earth Science, and Center for Nonlinear and Complex Systems, Duke University, Durham, North Carolina, USA.

Copyright 2007 by the American Geophysical Union. 0094-8276/07/2007GL031047
}

subtle promontories and embayments [Ashton and Murray, 2006a; Ashton and Murray, 2006b; Valvo et al., 2006]. Where shoreline curvature is convex seaward, such as at a promontory or plan-view bump, deep-water waves approaching shore from highly oblique angles $\left(>\sim 45^{\circ}\right)$ set up a convergent flux in alongshore sediment transport that causes the bump to accrete and grow; when deep-water waves approach convex-seaward shoreline features from smaller angles $\left(<\sim 45^{\circ}\right)$, they generate a divergent alongshore sediment-transport flux that causes promontories to erode [Ashton et al., 2001; Ashton et al., 2003; Falqués, 2003; Ashton and Murray, 2006a]. A wave climate dominated by high-angle waves is therefore an antidiffusive regime that tends to exaggerate plan-view shoreline features, while a low-angle or diffusive wave climate tends to smooth them out [Ashton and Murray, 2006a]. For a given time span, if gradients in alongshore transport cause shoreline change, a correlation between shoreline curvature and shoreline change should result, with a sign (positive or negative) that depends on whether high- or low-angle waves dominated the wave climate during that period.

[4] The degree to which cross-shore or alongshore transport drives shoreline change likely depends on the time and spatial scales over which change is measured; signals indicative of alongshore transport are only apparent when they dominate the higher-frequency, more localized sediment cycling of cross-shore transport processes. On the storm time scale of days to weeks, sand stripped from the beach is deposited in offshore bars that migrate landward with post-storm fair-weather swells, causing little net change to shoreline features [List and Farris, 1999]. If the effects of alongshore sediment fluxes become evident, at what scales in shoreline patterns does this occur? Previous analyses of shoreline change along the North Carolina Outer Banks suggest that shoreline curvature need not be pronounced for corresponding gradients in alongshore sediment transport to be effective [Ashton et al., 2003; Valvo et al., 2006]. Here we directly test this prediction, calculating and comparing shoreline change and curvature using annual lidar surveys of a long, continuous stretch of barrier island on northern flank of Cape Hatteras, North Carolina (Figure 1).

\section{Methods}

[5] We define areas convex (concave) seaward in plan view as having positive (negative) curvature. Shoreline position retreating landward is defined as negative change; where the shoreline aggrades seaward is positive change.

[6] For our measurements we extracted shorelines from U.S. Geological Survey and U.S. Army Corps of Engineers lidar surveys of the northern North Carolina Outer Banks 


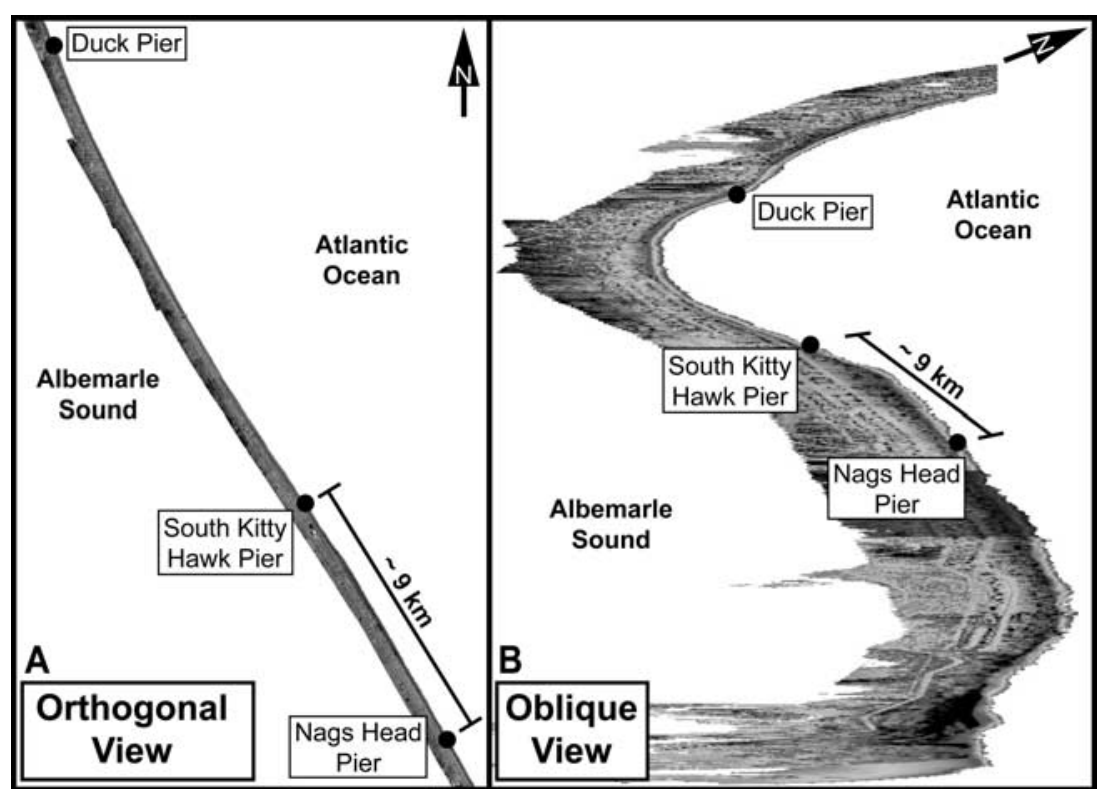

Figure 1. A lidar-derived DEM of the northern North Carolina Outer Banks, in (a) orthogonal and (b) oblique view. Note that even an apparently straight segment of shoreline (Figure 1a) has subtle curvature evident in Figure 1b.

collected in 1996, 1997, 1998, 1999, and 2005. Lidar instruments are flown in a small plane at low altitude $(\sim 1500 \mathrm{~m})$ and sweep a laser pulse over the land below; a receiver in the plane records the reflected laser return and processing software translates the returns into a high- resolution topographic map of the survey area. (An excellent lidar-sensor history and specifications summary is available through the NOAA Coastal Services Center, at www.csc.noaa.gov). Lidar is indispensable in lowlying topography such as coastal plains because the laser

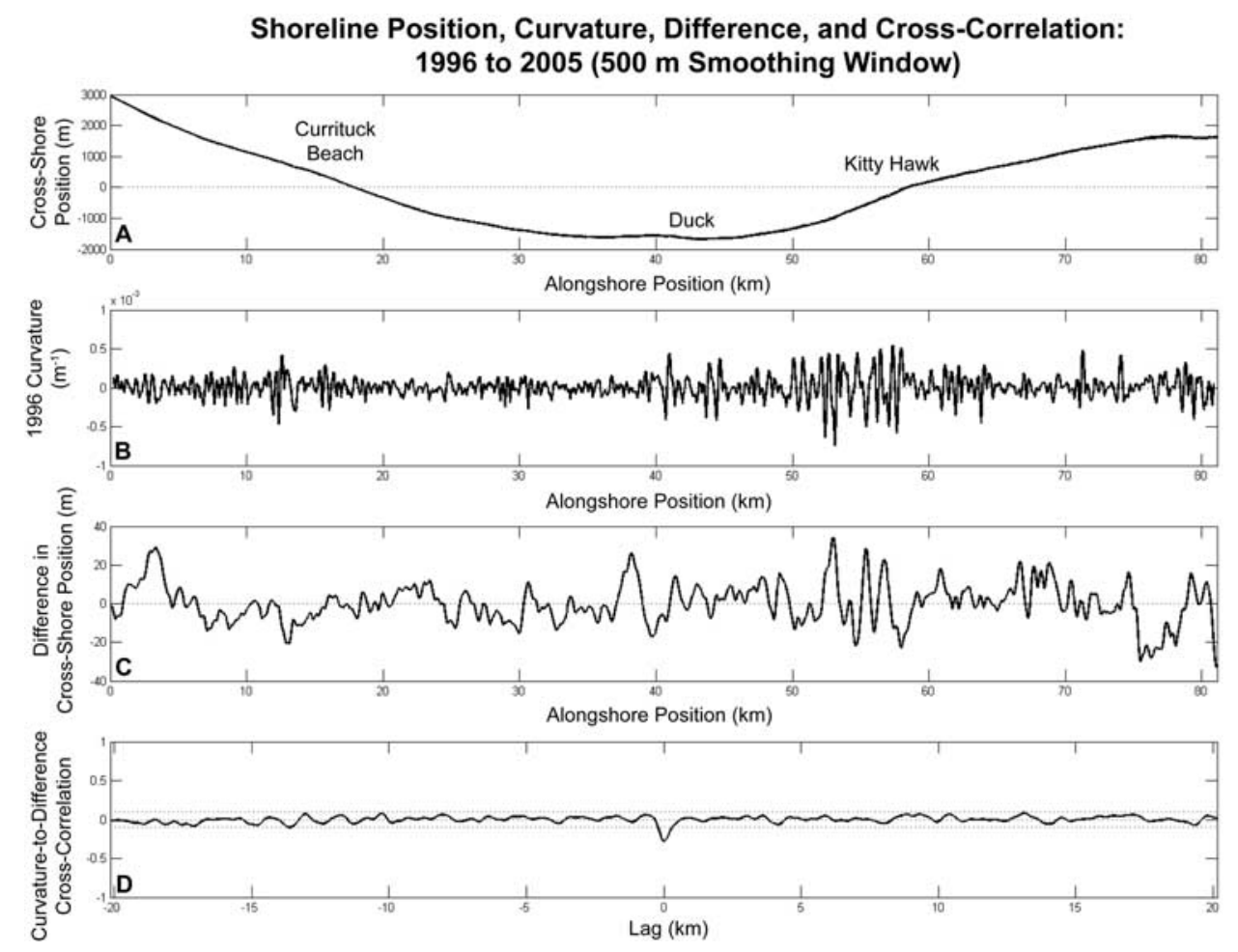

Figure 2. (a) Plots of shoreline position, labeled with general locations of Outer Banks towns, (b) 1996 shoreline curvature, (c) difference in shoreline position from 1996 to 2005, and (d) the cross-correlation between curvature and position difference, calculated for a $500 \mathrm{~m}$ smoothing window. In Figure 2d, the correlation peak at zero lag is outside the bounds of the $95 \%$ confidence interval, meaning the correlation between curvature and position change is robust. 
Shoreline Position, Curvature, Difference, and Cross-Correlation: 1996 to 2005 (2000 m Smoothing Window)
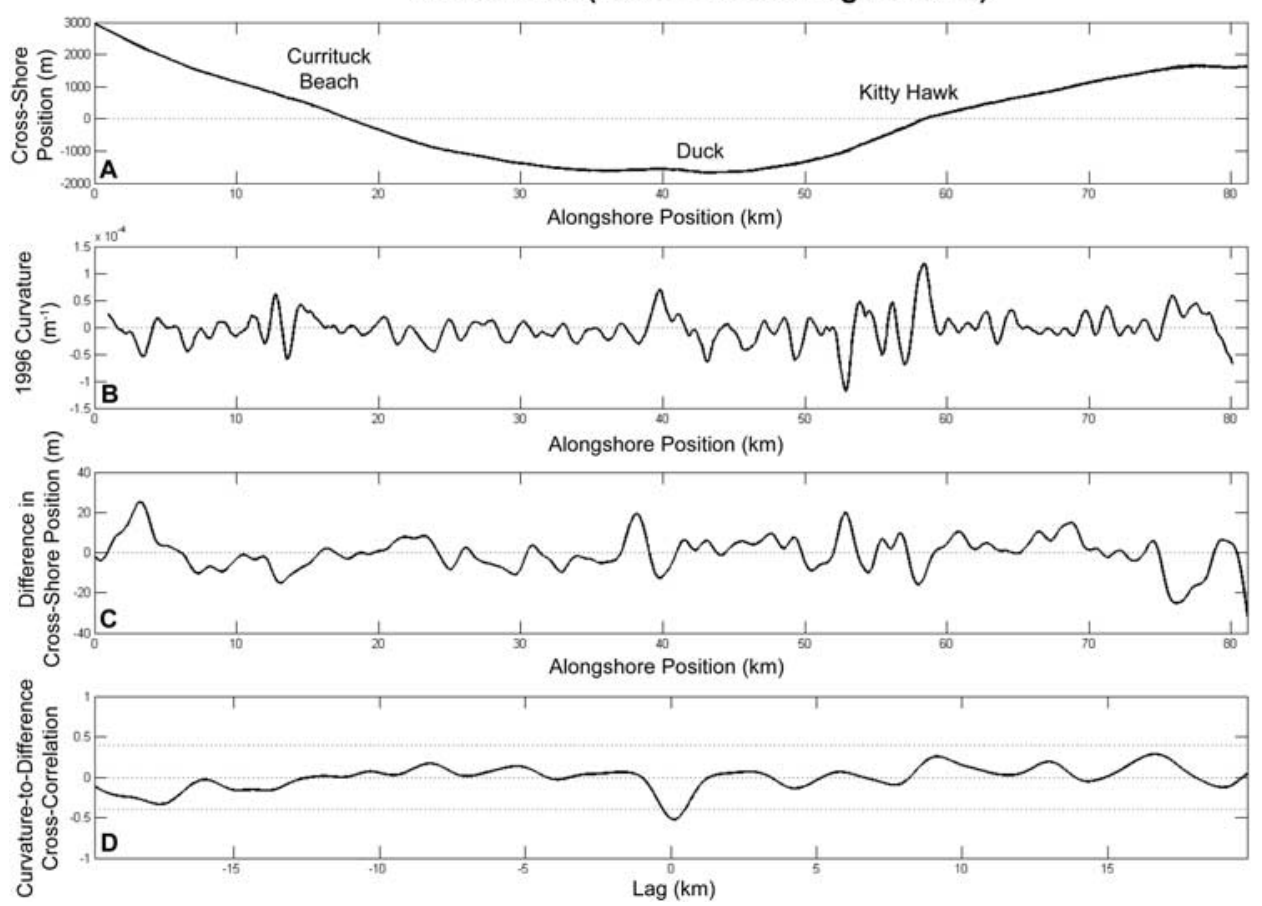

Figure 3. Plots same as in Figure 2, but calculated for a $2000 \mathrm{~m}$ smoothing window. Note that at this larger spatial scale for the 1996-2005 comparison, the correlation coefficient in Figure 3d is greater than in Figure 2d.

equipment can measure ground elevations to within $15 \mathrm{~cm}$ [Brock et al., 2002; Woolard and Colby, 2002; Sallenger et al., 2003].

[7] From the lidar DEMs we selected the $1 \mathrm{~m}$ elevation contour, as opposed to the zero or regional tide-adjusted contour [Weber et al., 2005; Tebbens et al., 2002], to represent the shoreline, minimizing wave-crest interference. (The elevation data are registered to the 1988 North American Vertical Datum.) We also cropped our survey area to reasonably exclude beach-restoration and hardstructure emplacement at the northern extent near False Cape, Virginia, and tidal-inlet influences at Oregon Inlet, North Carolina, to the south [Fenster and Dolan, 1996]. We are thus able to focus our analyses on the morphological effects of wave forcing over $85 \mathrm{~km}$ of continuous coastline.

[8] Rendering the shoreline as an array of planar coordinates, we subtracted the linear trend of the shoreline's original spatial orientation so that the alongshore direction corresponds to the $x$-axis and cross-shore to $y$ (Figures $2 \mathrm{a}$ and $3 \mathrm{a}$ ). The shoreline data points are spaced $5 \mathrm{~m}$ apart, an interval dictated by the horizontal accuracy of the lidar instrument [Brock et al., 2002; Woolard and Colby, 2002; J. Wozencraft, personal correspondence, 2006]. At such a small spacing, however, high-frequency undulations in shoreline position swamp more subtle, lower-frequency patterns. To isolate alongshore undulations up to the scale of several kilometers, we applied a series of sequentially larger smoothing windows that function as low-pass signal filters. In comparing shorelines from two different years, for each window size we calculated the curvature of the shorelines, where curvature $(\kappa)$ is defined as

$$
\kappa=\frac{\frac{d^{2} y}{d x^{2}}}{\left[1+\left(\frac{d y}{d x}\right)^{2}\right]^{\frac{3}{2}}}
$$

and $x$ and $y$ are alongshore and cross-shore position in meters, respectively (Figures $2 \mathrm{~b}$ and $3 \mathrm{~b}$ ). By linearly detrending each windowed shoreline segment before calculating $\kappa$, we reduce $d y / d x$ to zero and thus simplify curvature to the second derivative of the shoreline. We then found the difference in shoreline position between the surveys by subtracting the earlier positions from the later (Figures 2c and 3c), and cross-correlated the change in shoreline position with the curvature results (Figures $2 \mathrm{~d}$ and $3 \mathrm{~d}$ ), following the techniques and correlation functions described by Emery and Thompson [2004].

\section{Results}

[9] We find a persistent, robust negative correlation between shoreline curvature and shoreline-position change for $1-10 \mathrm{yr}$ time scales and spatial scales from 100-3000 m. The negative correlation suggests that areas of positive curvature (convex-seaward promontories) tend to exhibit negative change in shoreline position (erosion landward) 


\section{Curvature-to-Position Change Correlations for Smoothing Windows}

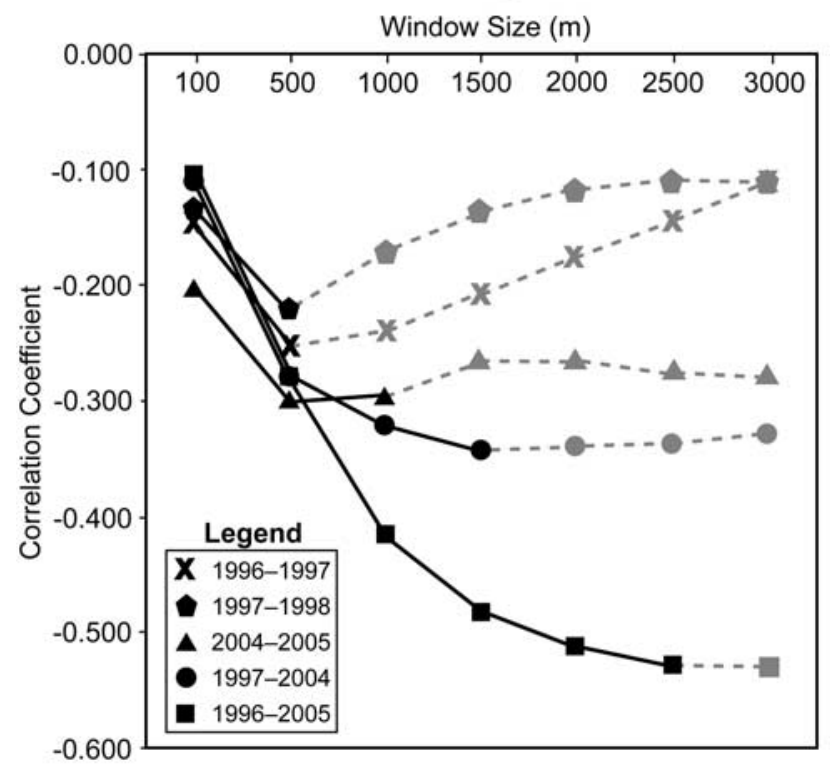

Figure 4. Plot showing curvature-to-position-change correlation coefficients versus window size for a range of year-to-year comparisons. At annual scales, correlation magnitudes reach a maximum around $500 \mathrm{~m}$; at neardecadal extents, the coefficients reach a maximum between 1000-3000 m. The correlation between curvature and shoreline-position change may be a signal of alongshore sediment-transport processes; stronger correlations at decadal and kilometer scales suggests that alongshore rather than cross-shore processes tend to dominate shoreline change over longer time intervals and larger spatial extents. Where lines are gray, correlation does not exceed the $95 \%$ confidence interval.

and vice versa. The result points to an overall diffusive smoothing of shoreline features.

[10] Figure 4 shows that correlations are strongest over long time intervals and at large spatial ranges, on the order of kilometers for the decadal extent of the data. For annual time intervals the correlation reaches a maximum at smaller smoothing-window sizes $(\sim 500 \mathrm{~m})$; for longer time intervals $(8-9 \mathrm{yr})$ the correlation reaches a maximum at larger smoothing windows $(1000-3000 \mathrm{~m})$. As the size of the smoothing window increases, the number of independent data points in the series decreases; the number of independent data points is so small beyond the correlationcoefficient maximum that the subsequent correlation coefficients at zero lag do not exceed the $95 \%$ confidence interval. (The confidence interval we employ is the extent to which we can reject the null hypothesis that there is no relationship between shoreline curvature and shorelineposition change.)

[11] As the smoothing window increases, undulations with an increasing alongshore wavelength are identified (e.g., Figure $2 \mathrm{~b}$ compared to Figure $3 \mathrm{~b}$ ), and the amplitude of those undulations remains approximately constant throughout the range of smoothing windows. This analysis confirms that the alongshore features in our study area do not exhibit a dominant spatial wavelength, a finding consistent with previous wavelet analysis of shoreline change in the same region [Tebbens and Nelson, 2000; Tebbens et al., 2002].

\section{Discussion}

[12] As a signature of alongshore sediment-transport processes, the correlation we find between curvature and shoreline-position change, though significant at annual and sub-kilometer scales, is strongest at decadal and kilometer scales, suggesting that alongshore transport processes tend to dominate shoreline change over long time intervals and large spatial extents while cross-shore or nearshore processes presumably dictate morphologic variation on shorter and smaller scales.

[13] The spatio-temporal relationship evident in the negative correlation is also consistent with the analytically predicted time scale for diffusion, in which time is proportional to the square of the length scale [Peldnare-Consideré, 1956; Ashton and Murray, 2006a]. With the negative correlations over annual time intervals strongest at spatial scales inside a kilometer and over decadal intervals at 2$3 \mathrm{~km}$, the smaller alongshore features exhibit change on shorter time scales than do the larger features.

[14] A negative correlation between shoreline curvature and shoreline-position change for the barrier-island coast between False Cape, Virginia, and Nags Head, North Carolina, dovetails with recent wave-hindcasting analysis for the northern Outer Banks documenting a predominantly a low-angle incident wave climate over the last two decades, and with the argument that the shadowing effects of largescale capes, such as those of the Carolinas, tend to create and maintain low-angle wave climates on their flanks [Ashton and Murray, 2006b]. Cape tips, which extend tens of kilometers offshore, shelter cape flanks from some of the antidiffusive influence of high-angle waves; along the flanks, steady forcing from a low-angle-dominated wave climate (over long enough time scales) will cause alongshore perturbations at all wavelengths to diffuse. The resulting process signal therefore should be the same at all spatial scales, as long as cape tips are not included. The negative correlation also supports numerical-modeling results suggesting that shoreline change over 20 years consists largely of shoreline-shape diffusion [Ashton et al., 2003].

[15] Though the correlation coefficients are small, a simple comparison experiment reinforces their validity. A complicating factor in comparing curvature and position change is that a bounded, noisy system produces an inherent negative correlation. Consider a set of randomized points sequestered between an upper and lower bound: if allowed to migrate over some time interval, points already situated near the margins cannot cross the boundary and therefore have a high probability of moving toward the interior of the envelope. The points nearest the bounds create areas of high curvature, so their probabilistic migration away from the boundaries reduces curvature and sets up a negative correlation between curvature and position change comparable to diffusion. Isolating signals diagnostic of alongshore transport processes thus requires differentiating those signals from a correlation attributable to noise. We generated two randomized datasets and processed them 
with the same steps and algorithms applied to the lidarderived shorelines. An unsmoothed randomized bounded dataset has a correlation coefficient of 0.5 ; with any smoothing, the correlation drops to zero.

[16] A bounded system, if an inappropriate analogy for a true shoreline, is at least a stringent null hypothesis. More complicating is that alongshore translation of features with a well-defined wavelength does give a negative correlation between curvature and shoreline change: Correlation magnitude increases as translation approaches half a wavelength, producing a maximum correlation at zero-lag in a cross-correlation analysis (as we observe at scales within $2 \mathrm{~km}$ ), making process signals difficult to differentiate.

[17] The diffusive influence of a low-angle wave climate for at least two decades begs the question why any bumps in the shoreline still persist (Figure 1). Their sustained existence outstrips an argument for simple diffusion, but may stem from heterogeneities in underlying shoreface lithology [Riggs et al., 1995, 1996; Cleary et al., 1999; McNinch et al., 2001; Honeycutt and Krantz, 2003; McNinch, 2004]. Integrated alongshore sediment-transport and geologic framework modeling by Valvo et al. [2006] offers evidence for the adjustment and persistence of lithology-related alongshore promontories and embayments in low-angle wave climate regimes, and predicts that correlations between curvature and shoreline-position change can switch from negative to positive on decadal time scales as the net diffusivity of the wave climate fluctuates about a mean. Given a steady wave climate and homogeneous shoreface substrate, our results would have predictive application for long-term shoreline change. However, variability in annual- to decadal-scale North Atlantic climate, in concert with lithological heterogeneity, confuses predictions of future shoreline position.

[18] Coastal change is one of the few circumstances in which geologic and political timelines intersect, and with mounting evidence for potential changes in storm frequency and severity in the future, ocean-side communities are facing increasingly difficult management dilemmas [e.g., Slott et al., 2006]. Investigation of shoreline evolution and eventual predictive capacity is therefore of immediate importance to land managers at all governmental levels making decisions about coastal public domain, beach restoration, and erosion response.

[19] Acknowledgments. Our thanks to the Joint Airborne Lidar Bathymetry Technical Center of Expertise (Kiln, Mississippi), the USGS Center for Coastal Geology (St. Petersburg, Florida), and the NSF (grant EAR 04-44792) for funding this research; and to Jordan Slott, Laura Fauver, Peter Howd, Jennifer Wozencraft, and Tommy Gerber for their critical insights and discussion.

\section{References}

Ashton, A. D., and A. B. Murray (2006a), High-angle wave instability and emergent shoreline shapes: 1. Modeling of sand waves, flying spits, and capes, J. Geophys. Res., 111, F04011, doi:10.1029/2005JF000422.

Ashton, A. D., and A. B. Murray (2006b), High-angle wave instability and emergent shoreline shapes: 2 . Wave climate analysis and comparisons to nature, J. Geophys. Res., 111, F04012, doi:10.1029/2005JF000423.

Ashton, A., A. B. Murray, and O. Arnoult (2001), Formation of coastline features by large-scale instabilities induced by high-angle waves, Nature, 414, 296-300.

Ashton, A., J. H. List, A. B. Murray, and A. S. Ferris (2003), Links between erosional hotspots and alongshore sediment transport, in Proceedings of the International Conference on Coastal Sediments 2003 [CD-ROM], World Sci., Corpus Christi, Tex.
Brock, J. C., C. C. Wright, A. H. Sallenger, W. B. Krabill, and R. N. Swift (2002), Basis and methods of NASA airborne topographic mapper lidar surveys for coastal studies, J. Coastal Res., 18, 1-13.

Cleary, W. J., C. D. Johnsen, M. K. Johnston, and M. Sault (1999), Storm impacts and shoreline recovery in S. E.N. C.: Role of the geologic framework, in Coastal Sediments '99: Proceedings of the 4th International Symposium on Coastal Engineering and Science of Coastal Sediment Processes, pp. 1798-1813, Am. Soc. of Civ. Eng., Reston, Va.

Emery, W. J., and R. E. Thompson (2004), Data Analysis Methods in Physical Oceanography, 2nd ed., 638 pp., Elsevier, Amsterdam.

Falqués, A. (2003), On the diffusivity in coastline dynamics, Geophys. Res. Lett., 30(21), 2119, doi:10.1029/2003GL017760.

Fenster, M. R., and R. Dolan (1996), Assessing the impact of tidal inlets on adjacent barrier island shorelines, J. Coastal Res., 12, 294-310.

Honeycutt, M. G., and D. E. Krantz (2003), Influence of the geologic framework on spatial variability in long-term shoreline change, Cape Henlopen to Rohoboth Beach, Delaware, J. Coastal Res., 38, 147-167.

Irish, J. L., and W. J. Lillycrop (1999), Scanning laser mapping of the coastal zone: The SHOALS system, ISPRS J. Photogramm. Remote Sens., 54(2-3), 123-129.

Irish, J. L., and T. E. White (1998), Coastal engineering applications of high-resolution lidar bathymetry, Coastal Eng., 35, 47-71.

List, J. H., and A. S. Farris (1999), Large-scale shoreline response to storms and fair weather, in Coastal Sediments '99: Proceedings of the 4th International Symposium on Coastal Engineering and Science of Coastal Sediment Processes, pp. 1324-1338, Am. Soc. of Civ. Eng., Reston, Va.

McNinch, J. E. (2004), Geologic control in the nearshore: Shore-oblique sandbars and shoreline erosional hotspots, Mid-Atlantic Bright, USA, Mar. Geol., 211, 121-141.

McNinch, J. E., J. T. Wells, and T. G. Drake (2001), The fate of artifacts in an energetic, shallow-water environment: Scour and burial of Queen Anne's Revenge, Southeast. Geol., 40, 19-27.

Mitasova, H., M. Overton, and R. Harmon (2005), Geospatial analysis of a coastal sand dune field evolution: Jockey's Ridge, North Carolina, Geomorphology, 72, 204-221.

Peldnare-Consideré, R. (1956), Essai de theorie de l'evolution des formes de rivage en plages de sable et de galets, in 4th Journees de l'Hydraulique, Les Energies de al Mer, vol. III-1, pp. 289-298, Soc. de Hydrotech. de Fr., Paris.

Riggs, S. R., J. C. Cleary, and S. W. Snyder (1995), Influence of inherited geologic framework on barrier shoreface morphology and dynamics, Mar. Geol., 126, 231-234.

Riggs, S. R., S. W. Snyder, A. C. Hine, D. L. Mearns, and S. W. Snyder (1996), Hardbottom morphology and relationship to the geologic framework of Onslow Bay, North Carolina continental shelf, J. Sediment. Res., $66,830-846$

Sallenger, A. H., et al. (2003), Evaluation of airborne topographic LIDAR for quantifying beach changes, J. Coastal Res., 19, 125-133.

Slott, J. M., A. B. Murray, A. D. Ashton, and T. J. Crowley (2006), Coastline responses to changing storm patterns, Geophys. Res. Lett., 33, L18404, doi:10.1029/2006GL027445.

Stockdon, H. F., A. H. Sallenger, J. H. List, and R. A. Holman (2002), Estimation of shoreline position and change using airborne topographic lidar data, J. Coastal Res., 18, 502-513.

Tebbens, S. F., and E. Nelson (2000), Wavelet analysis of shoreline change at Cape Hatteras National Seashore, Eos Trans. AGU, 81(48), Fall Meet. Suppl., Abstract NG62B-03.

Tebbens, S. F., S. M. Burroughs, and E. E. Nelson (2002), Wavelet analysis of shoreline change on the Outer Banks of North Carolina: An example of complexity in the marine sciences, Proc. Natl. Acad. Sci. U. S. A. 99(3), Suppl. 1, 2554-2560.

Valvo, L. M., A. B. Murray, and A. Ashton (2006), How does underlying geology affect coastline change? An initial modeling investigation, J. Geophys. Res., 111, F02025, doi:10.1029/2005JF000340.

Weber, K. M., J. H. List, and K. L. M. Morgan (2005), An operational mean high water datum for determination of shoreline position from topographic lidar data, U.S. Geol. Surv. Open File Rep., 2005-1027.

White, S. A., and Y. Wang (2003), Utilizing DEMs derived from LIDAR data to analyze morphologic change in the North Carolina coastline, Remote Sens. Environ., 85, 39-47.

Woolard, J. W., and J. D. Colby (2002), Spatial characterization, resolution, and volumetric change of coastal dunes using airborne LIDAR: Cape Hatteras, North Carolina, Geomorphology, 48, 269-287.

E. D. Lazarus and A. B. Murray, Division of Earth and Ocean Sciences, Nicholas School of the Environment and Earth Science, and Center for Nonlinear and Complex Systems, Duke University, Box 90229, Durham, NC 27708-0227, USA. (ed16@duke.edu) 